\title{
USING MULTI-CRITERIA DECISION MAKING TO DETERMINE THE CRITICAL SUCCESS F ACTORS FOR PROCUREMENT OF CAPITAL PROJECTS UNDER PUBLIC-PRIVATE PARTNERSHIPS.
}

\author{
Christian Tabi Amponsah \\ Faculty of Business and Management \\ University Canada West, Vancouver, BC, Canada \\ Email: chris_tabi@hotmail.com
}

\begin{abstract}
The investigation on project success has attracted the interest of many researches and practitioners. Determining the critical success factors for procurements of capital projects are contemporary phenomena. This paper presents the outcome of an investigation into the Critical Success Factors in Public-Private-Partnerships (P-P-P) for procurement of capital projects using Multi Criteria Decision Making process. Drawing on the results of responses from a survey of 705 experts involved in P-P-P projects worldwide, the paper presents the Critical Success Factors (CSF) from a list of 47 success factors identified as contributing to the successful delivery of capital project. The study revealed that owner satisfaction with the delivered project, adherence to schedules/budget/quality/ safety/environmental controls and appropriate funding mechanisms were predictable while lack of legal encumbrances, clearly defined project mission and adequate planning and control techniques were less commonly expected.
\end{abstract}

Keywords: Analytical Hierarchy Process, Critical Success Factors, Multi-Criteria Decision, Procurements, Public-Private Partnerships

\section{Introduction}

Despite well-known research results and despite column-miles of words that have been written about procurement of capital projects using Public-Private-Partnerships (P-P-P) model, and despite decades of individual and collective experience on managing P-P-P projects, project results continue to disappoint stakeholders. In the past, research has focused only on success factors either for the procurement of projects and best practices in dealing with success in project development. Presently, a pragmatic study is required to identify critical success factors for procurement of projects.

This paper presents the outcome of an investigation into the Critical Success Factors in P-P-P for procurement of capital projects using Multi Criteria Decision Making process. The subject of Critical Success Factors was selected for detail research because it represents areas or functions where events and actions occur to ensure successful competitive performance for an organization.

\section{Methodology}

The Multi Criteria Decision Method (MCDM) was leveraged for the study because of its significance in decision making when extensive number of factors are involved. MCDM as methodology has a precise language regarding the components of problem and the relationship between them. One such method of the MCDM is the Analytic Hierarchy Process (AHP) developed by Professor Thomas Saaty in 1987. Since its development, the AHP has been successfully applied to solve a wide range of multi-criteria decision-making problems. Some areas where AHP has been applied are: location analysis (Min, 1994), resource allocation (E.W.L. Cheng \& Li, 2001; Ramanathan \& Ganesh, 1995), outsourcing (Udo, 2000), evaluation (C.H. Cheng, 1997; Chin, Chui, \& Tummala, 1999; Davis \& Williams, 1994; Liang, 2003). 
Seven Hundred and five participants were listed from around the world and invited to participate in a survey including 267 from Canada, 175 from US, 82 from UK, 48 from Australia, 47 from the Middle East, 33 from Hong Kong, 18 from Africa, 18 from New Zealand, 10 from China, and 7 from Germany. Using the 705 experts comprising owners, project managers, consultants/contractors, financiers, and operators world-wide for procurement of capital projects, a model based on the Analytical Hierarchy Process was developed to investigate the Critical Success Factors. The respondents were targeted for seniority and their direct involvement in P-P-P. A pair-wise comparison was performed on 47 success factors derived from existing literature to determine the Critical Success Factors.

Factor analysis was used to identify factor groupings that can be used to represent relationships among sets of many inter-related variables (Kleinbaum, Kupper, \& Muller, 1988; Norusis, 1992). Saaty and Vargas (1991) identify two philosophical foundations for grouping success-related factors under separate sub-hierarchies. First, factors of similar nature should logically be grouped into one cluster to facilitate pair-wise comparison during the survey. Second it is known that an individual cannot simultaneously compare more than $7 \pm 2$ elements with satisfactory consistency and hence hierarchical decomposition is desirable (Saaty \& Vargas, 1991). The technique was applied to the list of success factors in this study to explore the groupings that might exist among the success factors. Morledge and Owen (1998) used six principal factors to group success factors for the investigations on critical success factors in public finance initiatives and the principal factors groupings have been adapted for this study. The response contributed to a wider feedback about the proposed factors without bias toward a particular group. Base on the criterion above, the 47 factors were grouped into six categories mainly, project participants, effective procurement, project implementation/characteristics, government guarantee, favourable economic conditions and available financial market. The questionnaire was then sent out requesting participants to identify, from a list, those factors which they agreed were critical in P-P-P projects.

\section{Data collection, analysis and results}

Survey data were collected from September 01, 2009 to November 20, 2009. The data were collected through interviews and were separated by the major factors and screened for different project participants. The Analytical Hierarchy Process (AHP) was used for detailed analysis of the data in the Expect Choice Theory software. The analysis helped to point out the critical success factors considered by each project participant for the construction industry. Agreement between different project participants was calculated using Spearman's and Kendall's technique.

\subsection{Validity and reliability of study}

Although, perfect consistency is hard to achieve, especially when considering multiple conflicting criteria, Analytical Hierarchy Process provided a mechanism of measuring the consistency of the decision made, and allowed for revisions of the decision to reach an acceptable level of consistency. In the AHP a measure of consistency of judgment is derived by means of Consistency Ratio (CR). If the value of the ratio is 0.1 or less, the decision is "good". If the value exceeds 0.1 , the judgment may somehow be random and should be revised (Saaty, 1990). Calculating the CR starts with multiplying each entry of the pair-wise comparison matrix by the relative priority (the average) corresponding to the column, and then totaling the row entries. Next, the row totals are divided by the corresponding entry from the priority vector. The average of those entries is the Eigen-value $\lambda \max$.

Consistency Index (CI) was then measured using the formula: $\mathrm{CI}=(\lambda \max -n)(n-1)$, where $n$ is the number of elements (factors) being compared in the matrix. The CI was then divided by its random index (RI) to get the consistency ratio, which indicated a measure of how much variation is allowed.

Spearman Correlation (rs) was primarily used to assess the correlation of the factors. Spearman R is the regular Pearson product-moment correlation coefficient (Pearson r); that is in terms of the proportion of variability accounted for, except that Spearman $\mathrm{R}$ is computed from ranks. Spearman correlation coefficient can range from -1.00 to +1.00 . On the lower side, -1.0 represents a perfect negative 
correlation, +1.00 represent a perfect positive correlation and 0.00 represents a lack of correlation. The spearman correlation was used to find and compare how well any two partic ipants agree while ignoring the third participant completely. The spearman correlation was calculated by the following formula (Thondike, 1978): rs $=1-6 \Sigma \mathrm{d}^{2} /\left(\mathrm{n}^{3}-\mathrm{n}\right)$, where:

rs $=$ The Spearman correlation

$\mathrm{d}=$ the difference between ranking for each group of judges

$\mathrm{n}=$ number of factors to be ranked

To assess the degree of association or agreement among sets of rankings, the Kendall coefficient of Concordance was measured. The Kendell coefficient of concordance $(\tau)$ is a measure of degree of association or agreement among sets of rankings. Range of the coefficient of concordance is from zero to one. One indicates a perfect agreement and zero indicates no agreement.

To calculate the Kendell coefficient, the data was first arranged into a ' $\mathrm{k}$ x n' matrix. Each row (n) representing ranks assigned by a particular judge (k) to (n) factors or aspects of a concept or problem.

Kendell coeffic ient was calculated using the following formula (Thondike, 1978):

$$
\tau=\frac{\sum_{i=1}^{k}\left(R_{i}-R\right)^{2}}{n\left(n^{2}-1\right) / 12}
$$

$\mathrm{R}_{\mathrm{i}}=$ Average of the ranks assigned by an individual

$\mathrm{R}=$ Average of the ranks assigned to the nth variable factor (sum of $\mathrm{R}_{\mathrm{i}} / \mathrm{n}$ )

$\mathrm{K}=$ Number of judgments

$\mathrm{n}=\quad$ the number of aspect of a problem or factor being ranked - in this study, 47 .

$\mathrm{n}\left(\mathrm{n}^{2}-1\right) / 12=$ the maximum possible squared deviations; i.e. the numerator which occurs if a perfect agreement among $\mathrm{k}$ set ranks and the average ranking are $1,2,3, \ldots \ldots \mathrm{n}$.

\subsection{Level of agreement between all partici pants recruited for the survey}

In order to assess the level of agreement between participants for the study, hypotheses were designed. Hypothetical testing relating to the level of agreement present between all the project participants i.e. Owners, Project Manager, Consultants/Contractor, Financier and Operators groups were performed.

Using Kendall coefficient of concordance $(\tau)$ depends upon the sample size (n). For values of $\mathrm{n}$ greater than 10 , standard error of $(\tau)$ is calculated using the following equation:

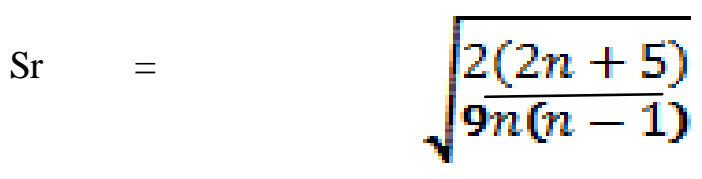

Test of statistics significance is calculated using the following equation:

$$
\mathrm{Z} \quad=\frac{\tau}{S r}
$$

Calculations are presented in the Table 1 for $(\mathrm{Ri}-\mathrm{R})$, which were used to calculate Kendall's coefficient of concordance. 
Hypotheses. Hypotheses are as follows:

$\mathrm{H}_{\mathrm{o}}$ : The Owners, Project Managers, Consultants/Contractors, Financiers and Operators are mutually independent in the ranking of major portion of the success factors.

$\mathrm{H}_{1}$ : The Owners, Project Managers, Consultants/Contractors, Financiers and Operators are not mutually independent in the ranking of major portion of the success factors.

Test statistics. The test statistics was calculated using equation (1), values of ( $\mathrm{Ri}-\mathrm{R})$ are obtained from Table 1. The sum (Ri-R) was obtained as 331.6, and the summation of (Ri-R) ${ }^{2}$ as 280.078 and the mean of $\mathrm{R}$ as 6.63 . With the value obtained, the Test statistics was calculated as follows:

$$
\begin{aligned}
\tau & =\frac{\sum_{i=1}^{\mathbf{3}}(280.0783)}{47\left(47^{2}-1\right) / 12} \\
\tau & =0.032
\end{aligned}
$$

Decision rule. Significance statistic was calculated using equation 2 and 3 as follows

$$
\begin{aligned}
& S_{r}=\sqrt{\frac{2(2 \times 47+5)}{9 \times 47(47-1)}} \\
& S_{r}=0.1 \\
& Z=0.032 / 0.1 \\
& Z=0.32
\end{aligned}
$$

To accept $\mathrm{H}_{0}$ the test statistic should be less than the significance statistic; otherwise the null hypothesis is rejected. The null hypothesis is accepted since $0.01<0.032$. At a significance level $(\alpha)$ of 0.05 or $95 \%$ confidence interval, it can be deduced that owners, project managers, consultants/contractors, financiers and operators do not agree on the rankings of major portion of the success factors. One quite obvious reason is that each group is working towards their own interest in the procurement of Public-Private Partnership projects.

\section{Conclusions, Implications and Recommendations}

The main purpose of the study was to determine critical success factors that could be used successfully for procurement of capital projects under P-P-P offering based on accumulated knowledge and judgment of experts including owners, project managers, consultants/ contractors, financ iers and operators.

The top 10 factors that were deduced from the success factor and considered critical are listed as follows:

1. Owner satisfaction with the delivered project

2. Clearly defined project mission, objective and scope definitions

3. Adequacy of plans and specifications

4. Lack of legal encumbrances

5. Appropriate funding mechanisms

6. Adequate planning and control techniques

7. Experience of Contractor/Consultant's team in P-P-P

8. Adherence to Schedules, Budget, Quality, Safety and Environmental Controls

9. Project Manager's commitment to establish budget and schedule

10. Effective communication throughout the project

The factors are listed in order of importance based on the outcome of analysis of the survey response. The top $5 \mathrm{CSF}$ on the list may be considered the most critical. From practical and professional standpoint, the findings should influence policy development towards P-P-Ps and the manner in which partners go about the development of P-P-P projects. With the topmost factor being owner satisfaction with the delivered 
project, the finding has important implication for developing P-P-P and at the conceptual stage of the procurement of Public-Private-Partnership project; parameters that are of ultimate concern to the owner must be given utmost attention. As long as the utmost factor is linked with the perceived need identified with a well-defined purpose and objective for the project, the project could be likely be successful. The study encircled experts in the construction industry belonging to five major groups, namely owners, project managers, consultants/contractors, financiers and operators, $w$ ith at least ten years experience in the construction industry. One of the issues that emerged from the findings was that greater proportions of participants were from consultant/contractor category followed by financiers. Some of the issues that emerged from the findings relate specifically to structuring of the financing and legislation for the procurement of P-P-P. As a result, construction management organizations can use those critical success factors to evaluate whether or not they should embark on development of capital projects. 
Table 1. Level of agreement between all participants

\begin{tabular}{|c|c|c|c|c|c|c|c|c|c|}
\hline \multirow{2}{*}{\multicolumn{2}{|c|}{$\begin{array}{l}\text { Kendall's data Correlation } \\
\text { Success Factor }\end{array}$}} & \multicolumn{5}{|c|}{ Ranking By } & \multirow{2}{*}{$\begin{array}{l}\text { Mean } \\
\text { Ri }\end{array}$} & \multirow[b]{2}{*}{ Ri-R } & \multirow[b]{2}{*}{$(\mathrm{Ri}-\mathrm{R})^{2}$} \\
\hline & & \multirow{2}{*}{$\frac{\text { Owner }}{6}$} & \multirow{2}{*}{$\begin{array}{l}\text { Project } \\
\text { Manager } \\
7\end{array}$} & \multirow{2}{*}{$\begin{array}{l}\text { Consultant/ } \\
\text { Contractors } \\
11\end{array}$} & \multirow{2}{*}{$\begin{array}{l}\text { Financier } \\
6\end{array}$} & \multirow{2}{*}{$\begin{array}{l}\text { Operator } \\
7\end{array}$} & & & \\
\hline SF \# 1 & Owner Enthusiasm & & & & & & 7.4 & 0.77 & 0.5929 \\
\hline SF \# 2 & $\begin{array}{l}\text { Owner commitment to establishing budget and } \\
\text { schedules }\end{array}$ & 6 & 9 & 4 & 6 & 9 & 6.8 & 0.17 & 0.0289 \\
\hline SF \# 3 & Owner satisfaction with the delivered project & 9 & 13 & 12 & '“"' & 13 & 11.2 & 4.57 & 20.8849 \\
\hline SF \# 4 & Project Manager's competency and authority & 8 & 10 & 11 & 8 & 10 & 9.4 & 2.77 & 7.6729 \\
\hline SF \# 5 & $\begin{array}{l}\text { Project Manager's commitment to establish budget } \\
\text { and schedule }\end{array}$ & 6 & 8 & 2 & 6 & 8 & 6 & -0.63 & 0.3969 \\
\hline SF \# 6 & Nature of the projects managers authority & 9 & 4 & 21 & 9 & 4 & 9.4 & 2.77 & 7.6729 \\
\hline SF \# 7 & $\begin{array}{l}\text { Capability of Contractor/Consultant's key persons to } \\
\text { establish Budget and Schedule }\end{array}$ & 8 & 8 & 16 & "'s"' & 8 & 9.6 & 2.97 & 8.8209 \\
\hline SF \# 8 & $\begin{array}{l}\text { Contractor/Consultants team commitment to budget } \\
\text { and schedule }\end{array}$ & 6 & 7 & 2 & 6 & 7 & 5.6 & -1.03 & 1.0609 \\
\hline SF \# 9 & Experience of Contractor/Consultant's team in P-P-P & 10 & "' & 16 & 10 & 9 & 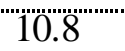 & 4.17 & 17.3889 \\
\hline SF \# 10 & Transparency in procurement process & 5 & 14 & 10 & 5 & 14 & 9.6 & 2.97 & 8.8209 \\
\hline SF \# 11 & Competitive procurement process & 4 & 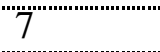 & 3 & 4 & "'? & "'s"' & -1.63 & 2.6569 \\
\hline SF \# 12 & $\begin{array}{l}\text { Thorough and realistic assessment of the cost and } \\
\text { benefits }\end{array}$ & 10 & 10 & 19 & 10 & 10 & 11.8 & 5.17 & 26.7289 \\
\hline SF \# 13 & Absence of bureaucracy & 6 & 3 & 10 & 6 & 3 & 5.6 & -1.03 & 1.0609 \\
\hline SF \# 14 & Meeting design goals & 4 & 3 & 1 & 4 & 3 & 3 & -3.63 & 13.1769 \\
\hline SF\# $\# 15$ & Efficient pre-contract activities & 9 & 4 & 14 & 9 & 4 & 8 & 1.37 & 1.8769 \\
\hline SF \# 16 & Satisfactory budget management (Profit and Loss) & 6 & 5 & 13 & 6 & 5 & 7 & 0.37 & 0.1369 \\
\hline SF \# 17 & Proper design Construction Interface management & 11 & 2 & 15 & 11 & 2 & 8.2 & 1.57 & 2.4649 \\
\hline SF \# 18 & Effective communication throughout the project & 8 & 7 & 14 & 8 & 7 & 8.8 & 2.17 & 4.7089 \\
\hline SF \# 19 & Effective communication throughout the project & 10 & 6 & 12 & 10 & 6 & 8.8 & 2.17 & 4.7089 \\
\hline SF \# 20 & Proper coordination between project professionals & 3 & 3 & 5 & 3 & 3 & 3.4 & -3.23 & 10.4329 \\
\hline SF"\# 21 & "Monitoring and feedback of project activities' & "'7"' & 4 & 17 & 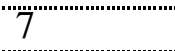 & 4 & 7.8 & 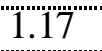 & 1.3689 \\
\hline SF \# 22 & Regular construction control meetings & 4 & 6 & 10 & 4 & 6 & 6 & -0.63 & 0.3969 \\
\hline SF \# 23" & Design and control meetings" & 1 & 5 & 3 & '"'l' & "'s" & 3 & -3.63 & 13.1769 \\
\hline SF \# 24 & $\begin{array}{l}\text { Adherence to Schedules, Budget, Quality, Safety and } \\
\text { Environmental Controls }\end{array}$ & 11 & 4 & 18 & 11 & 4 & 9.6 & 2.97 & 8.8209 \\
\hline SF \# 25 & Site limitation and location & 6 & 2 & 11 & 6 & 2 & 5.4 & -1.23 & 1.5129 \\
\hline
\end{tabular}


Table 1. (Continued) Level of agreement between all participants

\begin{tabular}{|c|c|c|c|c|c|c|c|c|c|}
\hline \multicolumn{2}{|c|}{ Kendall's data Correlation } & \multicolumn{5}{|c|}{ Ranking By } & \multirow{2}{*}{$\begin{array}{l}\text { Mean } \\
\text { Ri }\end{array}$} & \multirow[b]{2}{*}{ Ri-R } & \multirow{2}{*}{$(\mathrm{Ri}-\mathrm{R})^{2}$} \\
\hline \multicolumn{2}{|c|}{ Success Factor } & Owner & $\begin{array}{l}\text { Project } \\
\text { Manager }\end{array}$ & $\begin{array}{l}\text { Consultant/ } \\
\text { Contractors }\end{array}$ & Financier & Operator & & & \\
\hline SF \# 26 & Favorable legal framework & 2 & 4 & 3 & 2 & 4 & 3 & -3.63 & 13.1769 \\
\hline SF \# 27 & Project technical feasibility & 6 & 4 & 18 & 6 & 4 & 7.6 & 0.97 & 0.9409 \\
\hline SF \# 28 & Appropriate risk allocation and risk sharing & 9 & 5 & 19 & 9 & 5 & 9.4 & 2.77 & 7.6729 \\
\hline SF \# 29 & Strong private consortium & 12 & 4 & 11 & 12 & 4 & 8.6 & 1.97 & 3.8809 \\
\hline SF \# 30 & $\begin{array}{l}\text { Clearly defined project mission, objective and } \\
\text { scope definitions }\end{array}$ & 9 & 6 & 15 & 9 & 6 & 9 & 2.37 & 5.6169 \\
\hline SF \# 31 & Adequacy of plans and specifications & 6 & 8 & 5 & 6 & 8 & 6.6 & -0.03 & 0.0009 \\
\hline $\mathrm{SF} \# 32$ & Formal dis pute resolution process & 2 & 3 & 4 & 2 & 3 & 2.8 & -3.83 & 14.6689 \\
\hline SF \# 33 & Contractual motivation/incentives & 4 & 5 & 21 & 4 & 5 & 7.8 & 1.17 & 1.3689 \\
\hline SF \# 34 & Accurate initial cost estimates & 9 & 5 & 12 & 9 & 5 & 8 & 1.37 & 1.8769 \\
\hline $\mathrm{SF} \# 35$ & Adequate planning and control techniques & 2 & 6 & 0 & 2 & 6 & 3.2 & -3.43 & 11.7649 \\
\hline SF \# 36 & Minimal start-up difficulties & 3 & 4 & 17 & 3 & 4 & 6.2 & -0.43 & 0.1849 \\
\hline SF \# 37 & The perceive value of the project & 6 & 6 & 14 & 6 & 6 & 7.6 & 0.97 & 0.9409 \\
\hline SF \# 38 & Lack of legal encumbrances & 9 & 3 & 17 & 9 & 3 & 8.2 & 1.57 & 2.4649 \\
\hline SF \# 39 & $\begin{array}{l}\text { Minimized number of Public/government } \\
\text { agencies involved }\end{array}$ & 2 & 3 & 0 & 2 & 3 & 2 & -4.63 & 21.4369 \\
\hline SF \# 40 & Constraints imposed by end-users & 3 & 2 & 20 & 3 & 2 & 6 & -0.63 & 0.3969 \\
\hline SF \# 41 & $\begin{array}{l}\text { Government Involvement in providing a } \\
\text { guarantee }\end{array}$ & 8 & 5 & 10 & 8 & 5 & 7.2 & 0.57 & 0.3249 \\
\hline SF \# 42 & Multi-benefit objective & 5 & 3 & 1 & 5 & 3 & 3.4 & -3.23 & 10.4329 \\
\hline SF \# 43 & Stable macroeconomic conditions & 4 & 3 & 13 & 4 & 3 & 5.4 & -1.23 & 1.5129 \\
\hline $\mathrm{SF} \# 44$ & Sound economic policy & 5 & 3 & 15 & 5 & 3 & 6.2 & -0.43 & 0.1849 \\
\hline SF \# 45 & $\begin{array}{l}\text { Availability of a suitable and adequate financial } \\
\text { market }\end{array}$ & 7 & 5 & 15 & 7 & 5 & 7.8 & 1.17 & 1.3689 \\
\hline $\mathrm{SF} \# 46$ & Appropriate funding mechanisms & 8 & 8 & 15 & 8 & 8 & 9.4 & 2.77 & 7.6729 \\
\hline SF \# 47 & Confidence in project funding agencies & 12 & 6 & 9 & 12 & 6 & 9 & 2.37 & 5.6169 \\
\hline \multirow{2}{*}{\multicolumn{7}{|c|}{ Total $\sum$}} & & 331.6 & 280.078 \\
\hline & & & & & & & Mean R & 6.63 & \\
\hline
\end{tabular}




\section{REFERENCES}

Cheng, E.W. L., \& Li, H. (2001). Information priority-setting for better resource allocation using analytic hierarchy process. Information Management and Computer Security, 9 (2), 61-70.

Cheng, C.H. (1997). Evaluating naval teaching missile systems by fuzzy AHP based on the grade value of membership function. European Journal of Operational Research, 96(2), 342-350.

Chin, K.S., Chiu, S., \& Tummala, V.M.R. (1999). An evaluation of success factors using the AHP to implement ISO 14001-based EMS. International Journal of Quality and Reliability Management, 16(4) $341-361$

Davis, L., \& Williams, G. (1994). Evaluating and selecting simulation software using the analytic hierarchy process. Integrated Manufacturing System, 5 (1) 23-32.

Kleinbaum, D. G., Kupper, L.L., \& Muller, K. E. (1988). Applied regression analysis and other multivariable methods. Boston: PWS-KENT.

Liang, W.Y. (2003). The analytic hierarchy process in project evaluation: An R \& D case Study in Taiwan. Benchmarking, 10(5), 445-456.

Min, H. (1994). Location analys is of international consolidation terminals us ing the Analytic hierarchy process. Journal of Business Logistics, 15(2), 25-44.

Morledge, R., \& Owen, K. (1998). Critical success factors in PFI projects. In Hughes, W (Ed.), 14th Annual ARCOM Conference, 9-11, University of Reading. Association of Researchers in Construction Management, 2, 565-74.

Norusis, M.J. (1992). SPSS for Windows, Professional Statistics, Release 5. Chicago: SPSS Inc.

Ramanathan, R., \& Ganesh, L.S. (1995). Using AHP for resource allocation problems. European Journal of Operational Research, 80, 410-417.

Saaty, T. L., \& Vargas, L. G. (1991). Prediction, projection and forecasting. Kluwer, Boston: Academic Publishers.

Saaty, T. L. (1990). The analytical hierarchy process: Planning, priority setting and resources allocation. London: McGraw-Hill.

Udo, G.G. (2000). Using analytic hierarchy process to analyze the information technology outsourcing decision. Industrial Management and Data Systems, 100(9), 421-429. 